\title{
Control and Numerical Simulation of Natural Convection Benchmark Type in a Cavity Heated by Laser Beam Technique Emitted from a Single Slit Diffraction
}

\author{
Elhadj BENACHOUR*, Belkacem DRAOUI**, Bachir IMINE***, Khadidja ASNOUNE****, \\ Mohammed HASNAT****** \\ *Tahri Mohamed University of Bechar, Energarid Laboratory, B.P 417, 08000, Bechar, Algeria, \\ E-mail: benachour_elhadj@yahoo.fr \\ **Tahri Mohamed University of Bechar, Energarid Laboratory, B.P 417, 08000, Bechar, Algeria, \\ E-mail:bdraoui@gmail.com \\ ***Oran University of Science and Technology - Mohamed Boudiaf, El Mnaouar, BP 1505, Bir El Djir, \\ Oran, Algeria, E-mail: imine_b@yahoo.fr \\ ****Tahri Mohamed University of Bechar, Smart Grids Laboratory, B.P 417, 08000, Bechar, Algeria, \\ E-mail:kh_asnoune@yahoo.fr \\ *****Tahri Mohamed University of Bechar, Energarid Laboratory, B.P 417, 08000, Bechar, Algeria, \\ E-mail: mohammed.hasnat@yahoo.fr \\ crossref http://dx.doi.org/10.5755/j01.mech.25.3.22557
}

\section{Nomenclature}

$g$ - gravitational acceleration; $H$ - height of the cavity; $L-$ the length of the cavity; $C p$ - specific heat at constant pressure; $h$ - heat transfer coefficient; $N u$ - average Nusselt number; $t$ - time; $P$ - pressure; $T c$ - temperature of hot wall; $T f$ - the temperature of cold wall; $T$ - temperature; $X-\mathrm{di}-$ mensionless horizontal coordinates; $Y$ - dimensionless vertical coordinates; $\mu$ - Dimensionless horizontal velocity components; $v-$ : Dimensionless vertical velocity components; $P r$ - Prandtl number; $R a$ - rayleigh number; $\alpha$ - thermal diffusivity; $\beta$ - coefficient of expansion; $\Delta T$ - Temperature difference; $k$ - thermal conductivity; $\mu$-dynamic viscosity; $\rho$ - density.

\section{Introduction}

Oftentimes, the Electron Beam Machining and Laser Beam Machining are thermal processes considering the mechanisms of material removal. However electrical energy is used to generate high-energy electrons in case of Electron Beam Machining and high-energy coherent photons in case of Laser Beam Machining. Thus these two processes are often classified as electro-optical-thermal processes. Also, Laser Beam Machining or more broadly laser material processing deals with machining and material processing like heat treatment, alloying, cladding, sheet metal bending etc. Such processing is carried out utilizing the energy of coherent photons or laser beam, which is mostly converted into thermal energy upon interaction with most of the materials. Nowadays, laser is also finding application in regenerative machining or rapid prototyping as in processes like stereolithography, selective laser sintering etc. And remains the beam quality factor is a useful parameter for describing the propagation of different kinds of laser beams [1].

The laser surface heat treatment technique is widely spread in industry for the treatment of the engineering parts. To improve the heat treatment process, study of the heat transfer mechanism appropriate to the laser heating is necessary [2].
The laser, despite being a complicated phenomenon, is used for several materials and in several fields. Examples of this kind of research are found in the main journals which deal with technical aspects of laser beam, including International Journal of Heat and Mass Transfer [37], Lasers in Engineering [8-10], Advances in Mechanical Engineering [11], Materials and Design[12], Procedia Engineering [13]. Sometimes, Mathematical modeling and experimental methods have been used by researchers to understand, the optical effects of laser beam penetration in the aqueous humor. These models and experiments reveal the phenomena of thermal lensing of the laser beam, various methods have been proposed for the measurement of the M2 of lasers [14-19].

In addition, convection remains the most studied mode of heat transfer, whatever the cause, even if the type of convection changes: natural [20-22], mixed [23-25] or forced [26-28].

Also, multiphase flows are currently the subject of intense research, due to the broad application in industry [29-31]. At the same time, liquid-gas flows are very important from heat transfer enhancement point of view. This article also discusses the influence of laser source scarring on natural convection in a square cavity associated with a poor geometrical shape. The geometrical form of diffraction of light has been expressed by the law of Wien where the left wall is considered as a screen which receives electromagnetic waves. This approach is relatively new and should deserve special attention. This can be confusing. The radiation from a laser can raise the temperatures of things that absorb it, and common usage would call this "heating." But heat as the transfer of energy between two systems as a result of a temperature difference requires that the temperature of the system being heated be less than that of the heating system.

The temperature of the cavity where laser light is being produced and from which it is directed outward can be much less than the temperature of what gets heated by the laser light.

\section{Geometric configuration}

To solve this problem, the fluid is considered New- 
tonian and incompressible and the approximation of Boussinesq is presented. In addition, viscous friction is neglected.

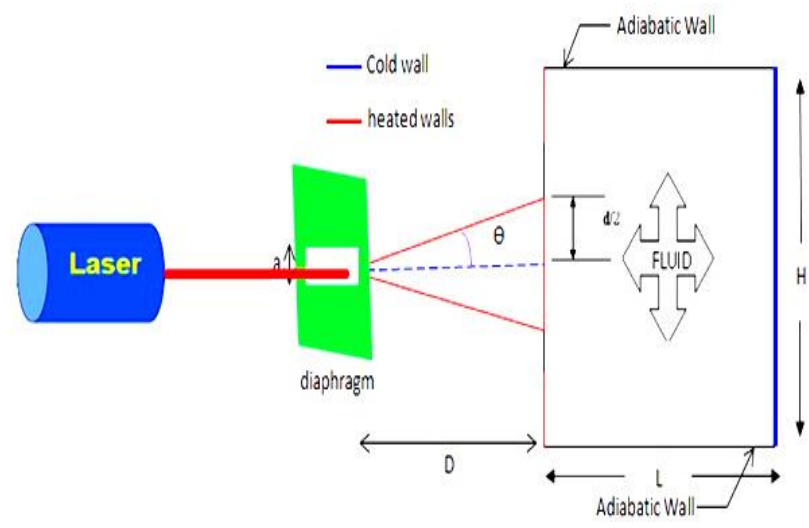

Fig. 1 The geometry considered

\section{Objectives}

lowing points:

We can express our aim for this study in the fol-

- Control of the wavelength of red laser light.

- Study of laser light effect on thermal convection.

- Calculate the heat transfer exchange coefficient in the diffraction center of the light.

\section{Mathematical modeling of convection}

The governing equations can be given by: Continuity equation.

$$
\frac{\partial \mu}{\partial X}+\frac{\partial v}{\partial Y}=0
$$

$X$-momentum equation.

$$
\frac{\partial \mu}{\partial t}+\mu \frac{\partial \mu}{\partial X}+v \frac{\partial \mu}{\partial Y}=-\frac{1}{\rho} \frac{\partial P}{\partial X}+v \nabla^{2} \mu .
$$

$Y$-momentum equation.

$$
\frac{\partial v}{\partial t}+\mu \frac{\partial v}{\partial X}+v \frac{\partial v}{\partial Y}=-\frac{1}{\rho} \frac{\partial P}{\partial X}+v \nabla^{2} v+g \beta \frac{\partial T}{\partial X}
$$

Energy equation.

$$
\frac{\partial T}{\partial t}+\mu \frac{\partial T}{\partial X}+v \frac{\partial T}{\partial Y}=\frac{K}{\rho_{C_{p}}} \nabla^{2} T .
$$

The derived Eq. (2) over $Y$ and the Eq. (3) over $X$, then, after subtracting the two equations obtained. The equations dimension-less variables in writing Helmotz in terms of vorticity and stream function formulation are given by:

$$
\begin{aligned}
& \frac{\partial \omega^{*}}{\partial \bar{t}}+U^{*} \frac{\partial \omega^{*}}{\partial \bar{x}}+V^{*} \frac{\partial \omega^{*}}{\partial \bar{y}}=\operatorname{Pr} \nabla^{2} \omega^{*}+\operatorname{Ra} \operatorname{Pr} \frac{\partial \bar{T}}{\partial \bar{x}}, \\
& \frac{\partial \bar{T}}{\partial \bar{t}}+U^{*} \frac{\partial \bar{T}}{\partial \bar{x}}+V^{*} \frac{\partial \bar{T}}{\partial \bar{y}}=\frac{\partial^{2} \bar{T}}{\partial \bar{x}^{2}}+\frac{\partial^{2} \bar{T}}{\partial \bar{y}^{2}},
\end{aligned}
$$

$$
\begin{aligned}
& \frac{\partial^{2} \psi}{\partial X^{2}}+\frac{\partial^{2} \psi}{\partial Y^{2}}=-\omega, \\
& \mu=\frac{\partial \psi}{\partial Y} ; v=-\frac{\partial \psi}{\partial X} ; \quad \omega=\frac{\partial v}{\partial X}-\frac{\partial \mu}{\partial Y} .
\end{aligned}
$$

Using the dimensionless variables in the equations above are defined by:

$$
\left\{\begin{array}{l}
\bar{x}=\frac{X}{L} ; \quad \bar{y}=\frac{Y}{L} ; \quad \psi^{*}=\frac{\psi}{a} ; U^{*}=\frac{\partial \psi^{*}}{\partial \bar{y}} ; \\
V^{*}=-\frac{\partial \psi^{*}}{\partial \bar{x}} ; \omega^{*}=\frac{\omega}{a / L^{2}} ;-\omega^{*}=\frac{\partial^{2} \psi^{*}}{\partial \bar{x}^{2}}+\frac{\partial^{2} \psi^{*}}{\partial \bar{y}^{2}} \\
\bar{P}=\frac{P}{\rho \mu^{2}} ; \bar{T}=\frac{T-T_{i}}{T_{c}-T_{i}} ; \bar{t}=\frac{t}{L^{2} / a} .
\end{array}\right.
$$

\section{The diffraction process}

The diffraction process is explained by the fact that light is a form of electromagnetic wave and the different portions of the slit behave as if they were separate sources of light waves - Huygens' principle. There is no simple expression for the location of the maxima on the screen other than that for the principal maximum at the central of the pattern. The other maxima are much less intense than the principal maximum and are located approximately halfway between the minima.

The diffraction pattern that appears on a screen will have an intensity variation above and below the slit as shown in Fig. 2.

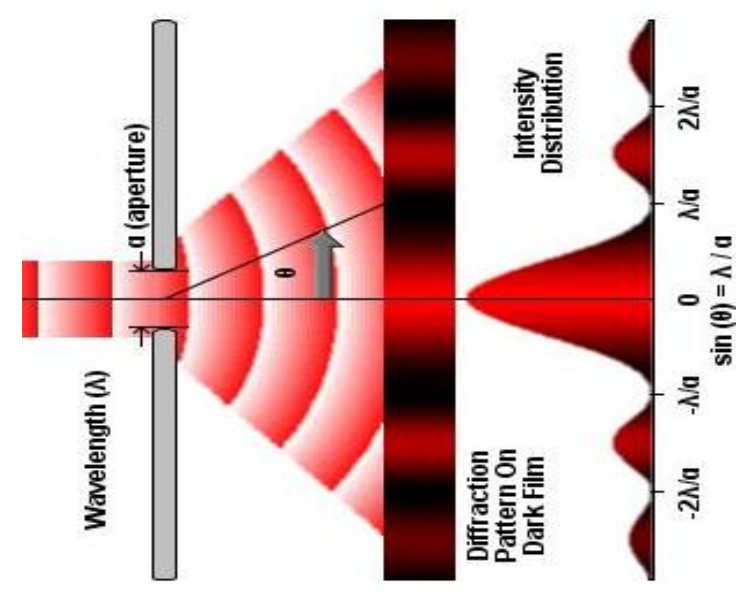

Fig. 2 Diffracted light intensity distribution with single Slit Diffraction

When light passes through a single slit whose width $w$ is on the order of the wavelength of the light, then we can observe a single slit diffraction pattern on a screen that is a distance $D \gg a$, away from the slit. The intensity is a function of angle. Huygens 'Principle tells us that each part of the slit can be thought of as an emitter of waves. All these waves interfere to produce the diffraction pattern. Where crest meets crest we have constructive interference and where crest meets trough we have destructive interference. So, the first diffraction minimum occurs at the angles given the first diffraction minimum occurs at the angles given by: 


$$
\sin \theta=\frac{\lambda}{a}
$$

The general equation for the points of zero intensity in the diffraction pattern of a single slit is:

$$
a \sin \theta=m \lambda ; \quad m=1,2,3 \ldots
$$

But usually we are just interested in the location of the first minimum, when $m=1$, because most of the light enery is located in the central diffraction maximum.

Let $y$ be the distance from the center of the central diffraction maximum to the first diffraction minimum.

The angle $\theta$ is related to this distance $y$ and the distance to the screen, $L$, by the equation:

$$
\tan \theta=\frac{y}{D}
$$

Since the angle $T$ is very small, $\cos \theta » 1$. Thus, $\tan \theta » \sin \theta$. Then, combining the above equation with equation (10), we have $\sin T=1 / a » y / D$, or:

$$
y=\frac{D \lambda}{a} .
$$

In other words, Wien's law tells us what color the object is brightest at. As the surface temperature rises, this peak intensity (brightness) shifts toward the bluer end of the spectrum. As the surface temperature decreases, the peak intensity/brightness will shift more towards the redder end of the spectrum as shown by the red dot in the picture below.

The wavelength of maximum emission of any body is inversely proportional to its absolute temperature (measured in Kelvin).As a result, as the temperature rises, the maximum (peak) of the radiant energy shifts toward the shorter wavelength (higher frequency and energy) end of the spectrum (bluer). This is what the equation looks like:

$$
\lambda_{\max }=\frac{2900}{T}
$$

Where $T$ is the absolute temperature in kelvins (K), displacement constant, equal to $2900 \mu \mathrm{m} \cdot \mathrm{K}$.

\section{Procedure of simulation}

Simple algorithm [30] is used to couple momentum and continuity equations.

The FLUENT software is used for this numerical simulation. For the convection terms, a first order of Apwind scheme. Also, we used a uniform grid of 16125 elements and 15876 nodes in non-stationary mode. given in Table 1 .

For the thermophysical properties of base fluids are

Table 1

Thermo physical properties of base fluid

\begin{tabular}{|c|c|}
\hline Physical properties & Air \\
\hline Temperature $^{\circ} \mathrm{K}$ & 288.15 \\
\hline Density, $\mathrm{Kg} / \mathrm{m} 3$ & 1.22 \\
\hline$C p, \mathrm{~J} / \mathrm{Kg}-\mathrm{K}$ & 1006.43 \\
\hline$\Lambda, \mathrm{W} / \mathrm{m}-\mathrm{K}$ & 0.0242 \\
\hline Viscosity, $\mathrm{Kg} / \mathrm{m}-\mathrm{s}$ & $1.7894 \mathrm{e}-5$ \\
\hline
\end{tabular}

\section{Validation}

Before continuing, it's required to ensure the dependability and the precision of the present numerical model and the FLUENT CFD code. The heat transfer data computed for differentially heated of the square cavity, with different parameters which correspond to the, aspect ratio $A 1=$ $=H / L$, Rayleigh number $10^{4} \leq R a \leq 10^{6}$. The present problem is to numerically investigate the natural convection flow. For the Validation of the model, our results were compared with those obtained by De Vahl Davis (1983) [20], (Table 2).

Table 2

Comparisons of the validation results

\begin{tabular}{|c|c|c|}
\hline Velocity & Present study & De Vahl Davis \\
\hline$U \max$ & 16.180 & 16.189 \\
\hline$V \max$ & 20.080 & 19.197 \\
\hline
\end{tabular}

It is clearly demonstrated in Table 2 that, for several values of Rayleigh number. Was checked and ensured with the present results and those obtained. There is a satisfactory agreement.

\section{Results and discussion}

The boundary conditions have been established to simulate a geometric configuration used frequently in twodimensional approximation.In this study, to target the most important goal, we will show and studied the dynamic and thermal behavior of the fluid in the square cavity.

\subsection{The isotherms}

The isotherms are presented in Figures [3 - 6]. The diffraction involves a change in direction of waves when they bounce off a barrier; this diffraction of waves involves a change in the direction of waves as they pass from one medium to another; also, the diffraction involves a change in direction of waves as they pass through an opening in a barrier in their path. Often, light waves have the ability to travel around corners, around obstacles and through openings. This ability is most obvious for light waves with

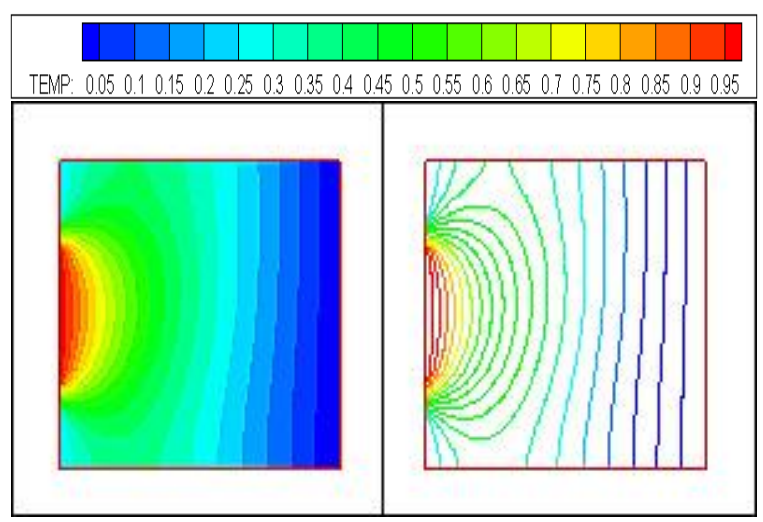

Fig. 3 The Isotherms for Rayleigh number $R a=1$. e3, $\operatorname{Pr}=$ $=0.71$

longer wavelengths, and in this case the temperature will be diffused even more based on the Wien law which presents the relativity between the temperature and the wavelength. We speak here of course to the central zone where the wavelength is maximum. And the temperature decreases with the 
decrease of the wavelength; it is also the case of the zones where the wavelength is minimum below the central zone and above this zone.

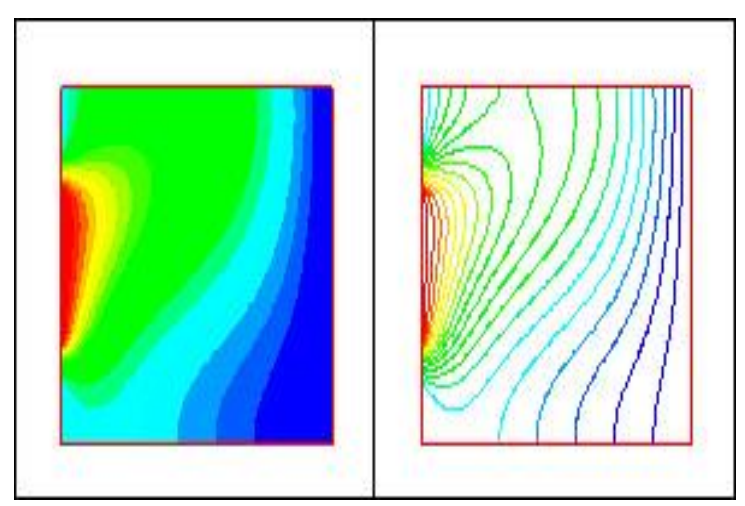

Fig. 4 The Isotherms for Rayleigh number $R a=1$.e4, $P r=$ $=0.71$

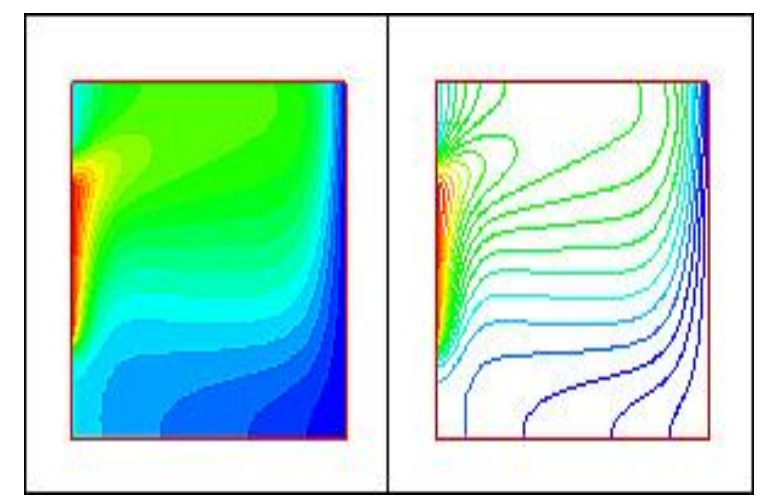

Fig. 5 The Isotherms for Rayleigh number $R a=1$. e5, $\operatorname{Pr}=$ $=0.71$

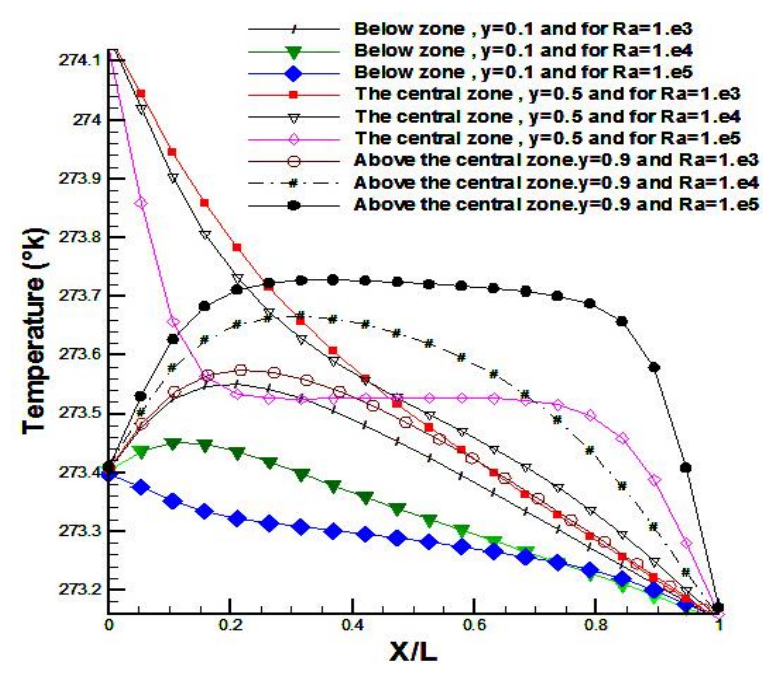

Fig. 6 The Isotherms profiles for different Rayleigh Numbers, $\operatorname{Pr}=0.71$

\subsection{Velocity profiles}

In general, changing the temperature due to wavelength diffraction, outer and inner limits cause the current lines to generate a cell in a clockwise direction for low Rayleigh numbers. For important Rayleigh numbers such as 1.e6, we notice the appearance of four circulation zones, a large zone in the center of the cavity contains two other zones in the middle that turn in a clockwise direction with low speeds, and a fourth zone of circulation that turns counterclockwise with a significant speed located to the left at the top. In the Fig. [7], we show the extraction of the velocity at half-height: $y=0.5$ or we notice that the velocity of the fluid is important at the border closer to the walls and it is stable in the center of the cavity.

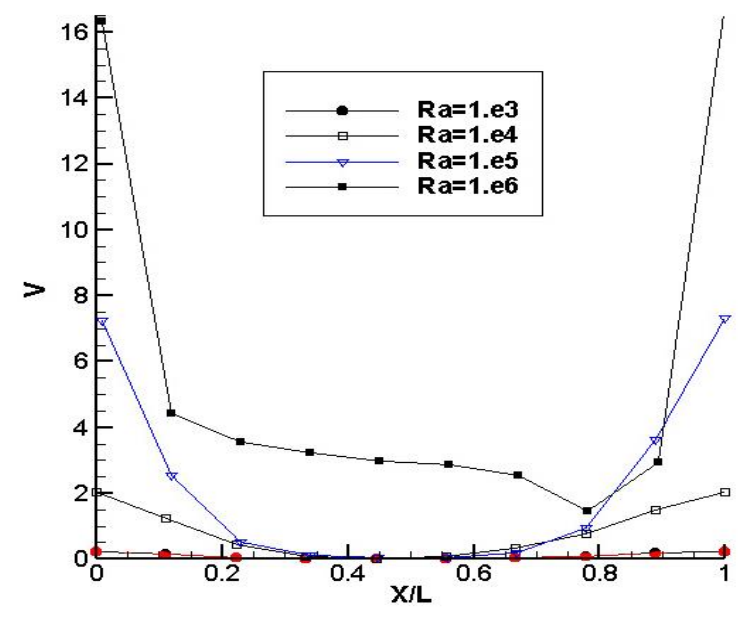

Fig. 7 Velocity profiles at $y=0.5$ for different Rayleigh numbers

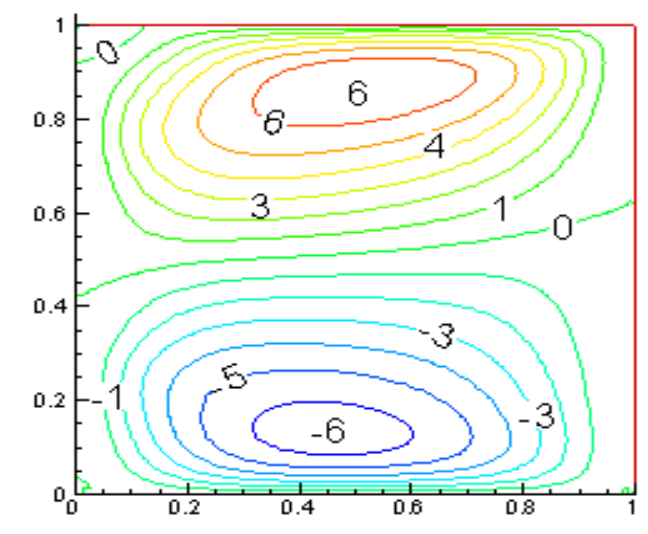

Fig. 8 Horizontal velocity contour for Rayleigh Number $R a=1 . e 4$

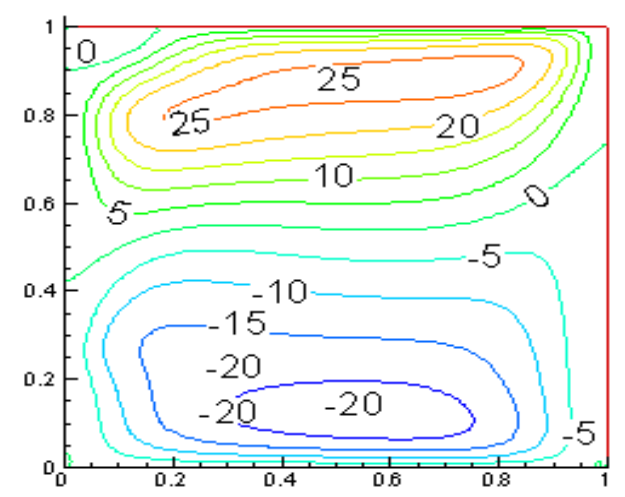

Fig. 9 Horizontal velocity contour for Rayleigh number $R a=1 . e 5$

The computed Horizontal velocity contours as well vertical velocity contours for $R a=10^{4}, 10^{5}$ are displayed in Figs. 8-11. It is observed that the velocity is zero at the center of the cavity and for the vertical velocity contours, the gradient increases near the left wall, where its closer to the source of central heat of the cavity as $R a$ increases. 


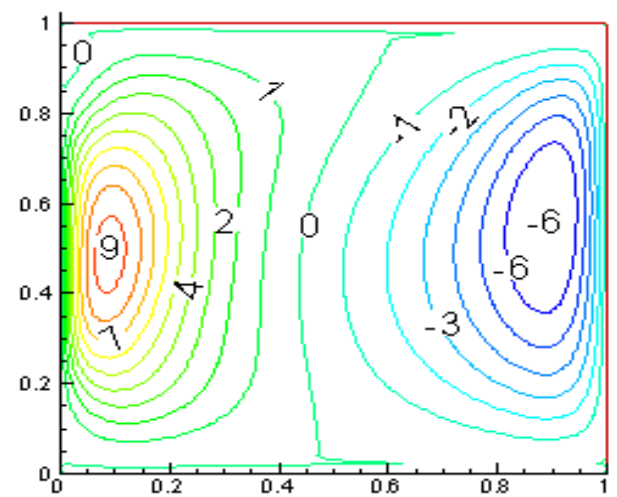

Fig. 10 Vertical velocity contour for Rayleigh number $R a=1 . e 4$

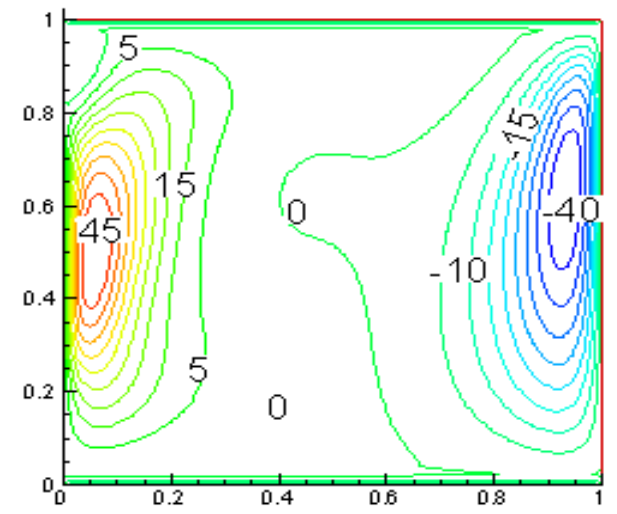

Fig. 11 Vertical velocity contour for Rayleigh number $R a=1 . e 5$

\subsection{Average Nusselt numbers}

Fig. 12 presents surface-averaged Nusselt number for various values of $R a$ number and for versus zones:

- central zone;

- below central zone;

- above the central zone.

So, above the central zone, The Nusselt number increases significantly with the increase in the number of Rayleigh, the number increases significantly with the increase in the number of Rayleigh Below the central zone is the opposite of this phenomenon which shows us the efficiency of the central zone which remains the main source of the heat diffusion inside the cavity (Fig. 12).

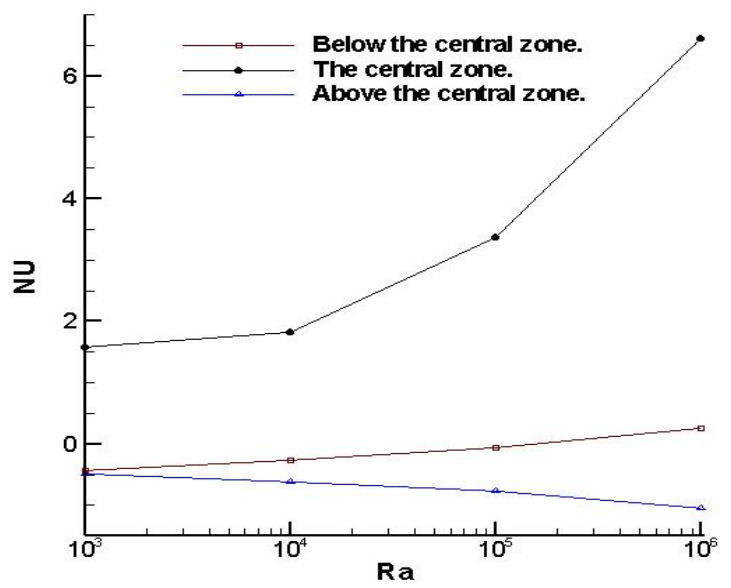

Fig. 12 Average Nusselt number for different Rayleigh Numbers in all intensity distribution zones
For the evolution of Nusselt number for different intensity distribution zone and for different Rayleigh Numbers are given in Table 3 :

Table 3

Average Nusselt number evolution for different intensity distribution zone and for different Rayleigh Numbers

\begin{tabular}{|c|c|c|}
\hline Zone type & $\begin{array}{l}\text { Rayleigh } \\
\text { numbers }\end{array}$ & $\begin{array}{c}\text { Nu number } \\
\text { (Average value) }\end{array}$ \\
\hline Above the central zone & $R a=1 . \mathrm{e} 3$ & -0.489 \\
\hline The central zone & $R a=1 . \mathrm{e} 3$ & 1.585 \\
\hline Below de central zone & $R a=1 . \mathrm{e} 3$ & -0.440 \\
\hline Above the central zone & $R a=1 . \mathrm{e} 4$ & -0.616 \\
\hline The central zone & $R a=1 . \mathrm{e} 4$ & 1.820 \\
\hline Below de central zone & $R a=1 . \mathrm{e} 4$ & -0.255 \\
\hline Above the central zone & $R a=1 . \mathrm{e} 5$ & -0.776 \\
\hline The central zone & $R a=1 . \mathrm{e} 5$ & 3.377 \\
\hline Below de central zone & $R a=1 . \mathrm{e} 5$ & -0.051 \\
\hline Above the central zone & $R a=1 . \mathrm{e} 6$ & -1.050 \\
\hline The central zone & $R a=1 . \mathrm{e} 6$ & 6.608 \\
\hline Below de central zone & $R a=1 . \mathrm{e} 6$ & 0.254 \\
\hline
\end{tabular}

\section{Conclusion}

In fact, visible 'light' is a form of radiation, which can be defined as an energy that travels in the form of electromagnetic waves.

This paper Presents new technique of heating of a square cavity based on the diffraction of the light emitted by monochromatic laser beam in order to study the convection and the air movement using variable heating.

So, this numerical study investigated the natural convection induced by a temperature difference witch also induced by the different intensity distribution of Laser Beam based on the Wien law. The dimensionless forms of the governing equations are modelled and solved using Fluent software. Detailed computational results for flow and temperature fields and the heat transfer are presented in graphical and profiles forms. follows:

The main conclusions of the present analysis are as

- The diffraction involves a change in direction of waves as they pass through an opening in a barrier in their path.

- The temperature decreases with the decrease of the wavelength.

- We notice that the velocity of the fluid is important at the border closer to the walls and it is stable in the center of the cavity.

- Mainly, the triggering of the convection is caused by the central zone which remains the motor of the movement of the fluid because of the maximum wavelength of the light waves.

We notice that the velocity of the fluid is important at the border closer to the walls and it is stable in the center of the cavity. Therefore, we can use this type of discontinuous heating if we are interested in a similar phenomenon of displacement of the fluid.

\section{Acknowledgments}

I would like to thank all reviewers for taking the time and energy to review our work. 


\section{References}

1. Lingqiang, M.; Qingqing, K.; Kunhao, J.; Zhigang, H.; Hua, S.; Rihong, Z. 2018. Characterization of beam quality of unstable laser beams with the multiple hyperbolas method, Results in Physics 12, 38-45, 17. https://doi.org/10.1016/j.rinp .2018.11.044.

2. Yilbas, B. S.; Shuja, S. Z. 1997. Heat transfer analysis of laser heated surfaces — conduction limited case, Applied Surface Science 108(1):167-175. https://doi.org/10.1016/S0169-4332(96)00570-3.

3. Kudryashov, S. I.; Samokhvalov, A. A.; Ageev, A. A. Petrov, E. I.; Veiko, V. P. 2018. Ultrasonic characterization of dry and wet nanosecond laser ablation of solids, International Journal of Heat and Mass Transfer 127(C): 1095-1100.

https://doi.org/10.1016/j.ijheatmasstransfer.2018.08.10 4.

4. Karthikeyan, A.; Coulombe, S.; Kietzig, A. M. 2018. Boiling heat transfer enhancement with stable nanofluids and laser textured copper surfaces, International Journal of Heat and Mass Transfer 126(B):287-296. https://doi.org/10.1016/j.ijheatmasstransfer.2018.05.118.

5. Kučera, M.; Martan, J.; Franc, A. 2018. Time-resolved temperature measurement during laser marking of stainless steel, International Journal of Heat and Mass Transfer 125: 1061-1068. https://doi.org/10.1016/j.ijheatmasstransfer.2018.04.37.

6. Jingxuan, M. Y.; Shoubin, L.; Yuxin, S.; Jialing, Y. 2018. Exact solution of thermal response in a three-dimensional living bio-tissue subjected to a scanning laser beam, International Journal of Heat and Mass Transfer 124: 1107-1116.

https://doi.org/10.1016/j.ijheatmasstrans-

fer.2018.04.042.

7. Kovalev, O. B.; Gurin, A. M. 2014. Multivortex convection of metal in molten pool with dispersed impurity induced by laser radiation, International Journal of Heat and Mass Transfer 68: 269-277.

https://doi.org/10.1016/j.ijheatmasstransfer.2013.09.031

8. Krystyna, K. S. 2010. Laser-beam modification of oxide thermal barrier coatings deposited by plasma spraying in air, Lasers in Engineering 12(4).

https://doi.org/10.1080/08981500 21000030111.

9. Martin, A. B.; Loredo, D.; Grevey, A.; Vannes, B. 2010. Numerical investigation of laser beam shaping for heat transfer control in laser processing, p. 247-269, published online: 18 Oct 2010.

https://doi.org/10.1080/0898150021000054539.

10. Maiwald, T.; Galun, R.; Mordike, B. L.; Feikus, F. J. 2010. Microstructure and corrosion properties of laser clads of magnesium base alloys for laser generated cylinder liners, p. 227-238, published online: 18 Oct 2010. https://doi.org/10.1080/0898150021000054511.

11. Robert, S.; Tomasz, G.; Agnieszka, S. 2018. The effect of laser welding power on the properties of the joint made of 1.4462 duplex stainless steel, January 2018, Advances in Mechanical Engineering 10(1): 16878140177 5194.

https://doi.org/10.1177/16878 14017751949.

12. Christian, H.; Martin, S.; Florian, F.; Rudolf, W.; Thomas, G. 2018. Optimization of the solidification conditions by means of beam oscillation during laser beam welding of aluminum, Materials and Design 160: 1178-1185, https://doi.org/10.1016/j.matdes.2018.11.009.

13. Jerzy, W.; Agata, M.; Elżbieta, G. 2016. Analytical description of the temperature field induced by laser heat source with any trajectory, Procedia Engineering 149: $553-558$. https://doi.org/10.1016/j.proeng.2016.06.704.

14. Neal, D. R.; Alford, W. J.; Gruentzner, J. K.; Warren, M. E. 1996. Amplitude and phase beam characterization using a two-dimensional wavefront sensor, Proc SPIE 2870:72-82. https://doi.org/10.1117/12.259947.

15. Du, Y.; Fu, Y.; Zheng, L. 2016. Complex amplitude reconstruction for dynamic beam quality M2 factor measurement with self-referencing interferometer wavefront sensor, Appl, Opt 2016; 55(36):10180-6. https://doi.org/10.1364/AO.55.010180.

16. Han, Z. G.; Meng, L. Q.; Huang, Z. Q.; Shen, H.; Chen, L.; Zhu, R. H. 2017. Determination of the laser beam quality factor (M2) by stitching quadriwave lateral shearing interferograms with different exposures. Appl Opt 2017, 56(27):7596-7603. https://doi.org/10.1364/AO.56.007596.

17. Du, Y.; Feng, G.; Li, H.; Cai, Z., Zhao, H.; Zhou, S. 2013. Real-time determination of beam propagation factor by Mach-Zehnder point diffraction interferometer, Opt Commun 287:1-5. https://doi.org/10.1016/j.optcom.2012.07.111.

18. Cortés, R., Villagómez, R.; Coello, B.; López, R. 2008. Laser beam quality factor (M2) measured by distorted fresnel zone plates, Rev MexFis 54(4):279-83.

19. Flamm, D.; Schulze, C.; Brüning, R.; Schmidt, O.A.; Kaiser; T.; Schröter, S. 2012 . Fast M2 measurement for fiber beams based on modal analysis. Appl Opt 2012 51(7):987-93. https://doi.org/10.1364/AO.51.000987.

20. Vahl, D. G. D. 1983. Natural convection of air in a square cavity: a bench mark numerical solution, Int. J. Numer, Methods Fluids 3:249-264. https://doi.org/10.1002/fld.1650030305.

21. Hasnat M.; Abdellah, B.; Kaid, N.; Benachour, E. 2017. Control volume finite element method for a benchmark validation of a natural convection in a square cavity, Energy Procardia 139: 511-516. https://doi.org/10.1016/j.egypro.2017.11.246.

22. Chan, K. F.; Leung, C. W. 1991. Natural-convection cooling of a housed, simulated printed-circuid board, Applied Energy 38: 245-252. https://doi.org/10.1016/0306-2619(91)90078-C.

23. Calmidi, V. V.; Mahajan, R. L.1998. Mixed convection over a heated horizontal surface in a partially enclosure, International Journal of Heat and Fluid Flow 19:358-367.

24. Pop, I.; Ingham, D. B.; Yuan, Y. 1996. Mixed convective conjugate heat transfer from a vertical flat plate, $\mathrm{Z}$. Angew, Math. Mech. 76(5): 281-289. https://doi.org/10.1002/zamm.19960760510.

25. Ali, M.; Al-Yousef, F.1998. Laminar mixed convection from a continously moving vertical surface with suction or injection, Heat and Mass Transfer 33: 301-306. https://doi.org/10.1007/s002310050193.

26. Vighnesam, N.V.; Soundalgekar, V.M .1998. Combi- 
ned free and forced convection flow of water at $4 \mathrm{C}$ from a vertical plate with variable temperature, Indian J. Engrg. \& Materials Sci. 5: 124-126.

http://nopr.niscair.res.in/handle/123456789/29589.

27. Soundalgekar, V. M.; Ramana, M. T. V.; Vighnesam, N. V. 1984. Combined forced and free convective flow of water at $4{ }^{\circ} \mathrm{C}$ past a semi-infinite vertical plate, International Journal of Heat and Fluid Flow. https://doi.org/10.1016/0142-727X(84)90017-1.

28. Shah, R. K. 1978. London, Laminar flow forced convection in ducts: a source book for compact heat exchanger analytical data, Academic Press, New York. https://lib.ugent.be/en/catalog/rug01:000698448.

29. Marcin, Z.; Robert, H.; Marek, J.; Anna, G. J.; Dariusz, Ś; Gholam, H. R. 2018. Analysis and interpretation of radiometric signals in a liquid-gas bubble flow, Proceedings of the International conference, Experimental Fluid Mechanics 2018, November 13-16, 2018 Prague, Czech Republic.

30. Patankar, S. V. 1980. Numerical Heat Transfer and Fluid Flow, McGraw-Hill New York. https://doi.org/ 10.1002/cite .330530323.
E. Benachour, B. Draoui, B. Imine, K. Asnoune, M. Hasnat

CONTROL AND NUMERICAL SIMULATION OF

NATURAL CONVECTION BENCHMARK TYPE IN A

CAVITY HEATED BY LASER BEAM TECHNIQUE

EMITTED FROM A SINGLE SLIT DIFFRACTION

S u m m a r y

Lasers are high-intensity beams that typically have a very pure frequency or wavelength. They come in sizes ranging from approximately one-tenth the diameter of a human hair to that of a very large.

There are many applications of lasers which benefit from a uniform optical intensity distribution.

Laser Beam is also a thermal process which includes the visible range of the electromagnetic spectrum. According to pilot study Huygens principle, we can approximate a particular wave front by assuming every point on it is a point source of light from a single slit diffraction. In this work, we based on the alternating distribution of the maximum intensity for the central zone and minimum for the secondary zones which allows us to control the dynamic and thermal field by the law of Wien. The idea is to combine the propagation of electromagnetic waves of light and the natural convection of fluids. The CFD software is used as a technique to modelling the behaviour of fluid and the thermal convection with different Rayleigh numbers. The results are presented in the form of distributions of the isotherms, the streamlines, local and average Nusselt .Thus these two processes are often classified as electro-optical-thermal processes.

Keywords: laser beam, natural convection, diffraction, laser light, heat transfer coefficient.

Received January 27, 2019

Accepted June 14, 2019 